\title{
Increasing the Likelihood of Consent in Deceased Donations: Point-of-Decision Campaigns, Registries, and the Law of Large Numbers
}

\author{
Tyler R. Harrison \\ Purdue University \\ USA
}

\section{Introduction}

The need for organ donation is growing while the number of those dying in ways to be eligible to donate (i.e. head trauma and auto accidents) is decreasing (Punch et al., 2007). In the U.S. alone there are over 111,000 people waiting for an organ transplant, with that number continuing to grow on an almost daily basis (United Network for Organ Sharing (UNOS), 2011). Additionally, over 7,000 individuals in the U.S. have died each year for the past ten years while waiting for a transplant, and over 100,000 have died within the past 15 years (Organ Procurement and Transplantation Network (OPTN), 2011). While few countries have been able to consistently increase the number of donors from year-to-year (with Spain being a notable exception), there are still large numbers of individuals who are eligible to donate and do not. One key factor in that helps explain lack of consent by family members to donation in the U.S. has been lack of knowledge of a deceased's wishes. When family members know of a desire to donate, rates of consent to donate are in the $85-95 \%$ range compared to $25-55 \%$ when they do not know the deceased's wishes (e.g. Rodrigue et al., 2005; Siminoff \& Lawrence, 2002). Additionally, some research has shown that knowing an individual's wishes to donate made the family 6.9 times as likely to consent to donation (Siminoff \& Lawrence, 2002). Thus, increasing declarations of intent or consent through registries is one way to insure family members know of a loved one's wishes to donate.

In the U.S. there is a rapidly growing body of research focusing on campaign strategies to increase the number of individuals who have declared their intent to donate. While many of these campaigns are successful (e.g. Feeley et al., 2009; Morgan et al. 2002; Morgan, Harrison, et al., 2010), many also suffer from limited reach or impact (e.g. Quinn et al. 2006; Fahrenwald et al., 2010), and may thus be a questionable use of resources for non-profit organ procurement organizations. While new strategies such as social media (i.e. facebook) are being investigated for their ability to generate new potential donors, the results of those studies are not yet know. However, a series of recent studies (Harrison et al., 2008; Harrison et al., 2010; Harrison et al., 2011; King et al., under review) have demonstrated the ability to overcome this limited reach and provide dramatic increases in the rates of joining organ donor registries (ranging from 200\% to over 500\% with net increases in the tens of 
thousands of new registrations) by utilizing point-of-decision campaigns targeting potential donors at Division of Motor Vehicles (DMV) offices where individuals apply for driver's licenses. These campaigns have taken advantage of the large push by HRSA/DoT to establish registries in every state in the U.S., and many of these registries are operated through DMVs or their equivalents.

Utilizing estimates on family consent rates, this chapter explores differences in potential rates of donation to demonstrate how increasing the number of individuals who have declared their intent to become donors can significantly increase rates of organ donation. Additionally, this chapter explores the importance of registries and examines different approaches to increase the number of individuals who join organ donor registries at DMV branches. These strategies include: training clerks how to ask individuals to join the registry and address myths the public may express; focused volunteer trainings of people touched by donation with an emphasis on persuading the public to become donors by communicating effectively their stories of donation, addressing myths and barriers to donation, and providing mechanisms for action; point-of-decision campaign materials to establish normative influence, address barriers, and prompt action; and mass media campaigns to prime individuals to take action to be a donor when they utilize DMVs. The relative effectiveness (both in terms of creating new registrations as well as cost per registration) of these strategies is explored in this chapter.

While these campaigns have largely been conducted in the U.S., a review of barriers to donation internationally reveals similar barriers, although with culturally specific differences to those found in the U.S. (e.g. Conesa et al., 2006; Molzahn et al., 2005; Topbas et al., 2005), especially among minority populations. Many of the campaign strategies discussed in this chapter are easily modified to address different cultural and national concerns, and this chapter presents suggestions for adapting campaign strategies and materials to address these differences. Ultimately, we argue for the importance of registries (in non-presumed consent countries) and focused point-of-decision and interpersonal campaigns for use internationally.

\section{The law of large numbers: DMV-based registries and potential consent and recovery rates}

In 2002 The Lewin Group concluded that the "effectiveness" of donor registries could not yet be established, largely as a function of the relatively short period of time that registries have been in existence. Since that time, almost every state in the U.S. has developed either a $\mathrm{DMV}$, internet, or DMV/Internet based registry. While many states have created registries, the rate of individuals joining these registries varies dramatically. For example, at the start of a recent project to increase rates of joining the registry in Michigan, only about $11 \%$ of individuals had joined the Michigan Organ Donor Registry (Harrison et. al. 2010). While this number has since increased dramatically, the percentage is still very low compared to the over $70 \%$ of the public who have joined the registry in Utah, Montana, Alsaka, Oregon, and Washington. On average, $40 \%$ of Americans have joined an organ donor registry to date. (Donate Life America, 2011). However, some OPOs are reluctant to put resources towards public education campaigns to increase registries, perhaps because of a lack of full understanding of the report, and the belief that registries are not effective. For many, the current definition of a successful registry appears to necessitate yielding actual organ 
donors; this is not appropriate given the current level of registry utilization and the number of years that registries have existed. If we accept the statistics that approximately $1 \%$ of the population will die in such a way that they could become a potential donor, states with only ten thousand registrants can be expected to yield a maximum of 100 potential donors over the registrants' lifetime. Comparatively, states with 1,000,000 registrants can expect to have 10,000 potential donors over the course of a lifetime. Complaining that a registry has yielded only one or two donors since a registry was established a few years ago is tragically shortsighted given the long-term potential of registering large numbers of confirmed potential donors through DMVs.

Obviously, though, some individuals would become organ donors regardless of the presence of state registries. One indication that donor registries can be a highly efficacious way to increase the number of actual donors comes from HRSA/DoT funded project conducted with Intermountain Organ Recovery System in Utah. The project began in 2002 consisted of both media and grassroots activities. The results were dramatic. The percentage of Utahans between 16 and 74 registering to become donors rose from $58.4 \%$ to $63 \%$. While a $4.6 \%$ increase may seem modest, it represents an additional 70,224 potential donors in just less than three years bringing the total number of people registered as donors to over one million. Of all medically eligible deaths, $97 \%$ of people on the registry went on to become donors, while only $61 \%$ of non-registrants became donors. Further, the importance of using the DMV as a portal for entry to the registry was demonstrated: $99 \%$ of registrants came from the DMV, while comparatively very few signed up online (Health Resources Services Administration (HRSA), 2006).

A few examples may be useful to illustrate the full potential of how increasing the number of individuals who have declared their intent to become organ donors can actually increase the number of organ donors. Obviously, calculations of potential donors are based on many assumptions. The calculations presented below use a consent rate of $50 \%$ if the family does not know the wishes of the deceased, and 95\% if they do (with over 36 states having passed first person consent laws (Donate Life America, 2011), and many OPOs moving toward enforcing first-person consent laws, this number is likely to be on the low side). Additionally, the calculations assume that 1 in 100 individuals will die in a way to make them eligible to become a donor. Further, the calculations assume an average of 3 organs are recovered from each donor. Assuming a population of 5 million, over the course of a lifetime we can expect 50,000 potential donors and 150,000 potential organs to become available for transplantation. With these assumptions in mind the table below illustrates potential consent and organ recovery rates for registries with 11\% (low), 40\% (current average), and $76 \%$ (current high) of the population having declared their intent to donate.

While there is certainly room to adjust the assumptions in these calculations (in either direction), these figures provide an excellent illustration of the law of large numbers in relation to organ donation registries, and the need to judge the effectiveness of registries over extended periods of time. Using these assumptions, a state with a current population of $5,000,000$ and a well-filled organ donor registry could potentially save an additional 51,300 lives through transplantation compared to a state with no registry. Additionally, in the absence of in-house medical transplant procurement managers, such as in the Spanish Model (Vidal et al. 2007), well-filled registries are likely to provide consent rates at or above those found in Spain. Thus, there seems to be ample indication that donor registries have the 
potential to serve a very important role in increasing the rate of organ donation in the U.S. and other countries.

\begin{tabular}{|c|c|c|c|}
\hline $5,000,000$ population & $\begin{array}{l}11 \% \\
\text { Registered } \\
\text { Donors }\end{array}$ & $\begin{array}{l}40 \% \\
\text { Registered } \\
\text { Donors }\end{array}$ & $\begin{array}{l}76 \% \\
\text { Registered } \\
\text { Donors }\end{array}$ \\
\hline $\begin{array}{l}\text { Number of individuals on } \\
\text { registry }\end{array}$ & 550,000 & $2,000,000$ & $3,800,000$ \\
\hline Number of consents from registry & 5,225 & 19,000 & 36,100 \\
\hline $\begin{array}{l}\text { Number of consents not on } \\
\text { registry }\end{array}$ & 22,250 & 15,000 & 6,000 \\
\hline Total number of consents & 27,475 & 34,000 & 42,100 \\
\hline $\begin{array}{l}\text { Total \% of consents per eligible } \\
\text { donors }\end{array}$ & $54 \%$ & $68 \%$ & $84 \%$ \\
\hline $\begin{array}{l}\text { Number of potential organs } \\
\text { recovered }\end{array}$ & 82,425 & 102,000 & 126,300 \\
\hline Number of consents if no registry & 25,000 & 25,000 & 25,000 \\
\hline Consents as a result of registry & 2,475 & 9,000 & 17,100 \\
\hline $\begin{array}{l}\text { Potential organs recovered as a } \\
\text { result of registry }\end{array}$ & 7,425 & 27,000 & 51,300 \\
\hline
\end{tabular}

Table 1. Examples of potential rates of consent and organ recovery by percentage of public on registry based on population estimate of 5,000,000

\section{Filling organ donor registries}

When looking at the numbers for an average size state in the U.S., getting 3.6 million individuals to join an organ donor registry is obviously an enormous task. The structure of the registry itself is very important, as are strategies to encourage individuals to join the registry.

DMVs that operate organ donor registries possess two key characteristics that give them substantial advantages over other venues for implementing campaigns to join donor registries. First, they reach almost all individuals over 16 years of age. Most DMVs require individuals to come in person to obtain their first driver's license or state ID card, and many require return visits every four to six years for renewals. Thus, in many states tens of thousands of individuals come through branch offices on a monthly basis. Reaching this large of a population through any other sort of intervention would be almost impossible. Second, at DMVs in states that host registries, individuals actually have to make a decision about whether to declare their intent to become organ donors. Many states require clerks in branch offices to ask members of the public if they want to join an organ donor registry. At that point and individual must decide either yes or no. Campaigns in worksites, public health fairs, flea markets, or elsewhere do not actually mandate decision-making. If an individual is unsure of their intentions toward donation they can delay their decision; this option to delay decisions may be a factor that contributes to the relatively low rates of signups at many community outreach events. Targeting individuals at a place and time when a decision is required is likely to help those who are favorable but undecided to declare their intentions to become a donor. 


\subsection{Public education strategies to fill organ donor registries}

Over the past decade, also largely as a result of funding from HRSA/Division of Transplantation, there has been tremendous growth in the U.S. in the creation and evaluation of campaigns to increase the number of individuals declaring their intent to become organ donors. Rather than reviewing the growing body of literature focused on worksite interventions, university-based campaigns, or community outreach events, the following section focuses specifically on campaigns targeting DMV branches. While campaigns in DMVs are successful at reaching large numbers, the limited amount of time spent in DMV branch offices limits the amount of information an individual is likely to process. Individuals who have substantial objections to donation may need more information or more time to be persuaded before declaring their intentions to donate. Thus, DMV campaigns may not be able to persuade those who have substantial objections to donation, suggesting the need for ongoing or more in-depth campaigns (such as those discussed in Morgan's chapter in this volume) to affect attitude and behavior change. However, getting large numbers of individuals on an organ donor registry should be a major priority given the potential increases in consent rates.

A series of recent campaigns have worked toward developing best practices to increase rates of joining organ donor registries by targeting both employees and members of the public at DMV branches. These campaigns include a pilot study in Charlotte, North Carolina focusing primarily on point-of-decision materials targeting African Americans at DMV branch offices (Morgan, unpublished manuscript); clerk trainings at DMV branches in multiple counties across Kentucky (Harrison et al., 2008) and Florida (Rogrigue et al., under review); and a series of phased interventions across Michigan targeting the general public and featuring point-of-decision materials, an interpersonal component, and a mass media intervention (Harrison et al. 2010; Harrison et al. 2011; King et al. under review).

\subsubsection{African Americans and organ donor registries in North Carolina}

The reasons for African Americans' reluctance to donate have been the subject of considerable speculation. In addition to lack of awareness and lack of knowledge (Morgan et al., 2003; Yancey et al., 1997), religion (Reitz \& Callender, 1993; Wittig, 2001; Yancey, et al., 1997) preference for directed donation (Arnason, 1991; Hall, et al., 1991; Lange, 1992; Reitz \& Callender, 1993), medical mistrust (e.g. McNamara, et al., 1999; Plawecki, et al., 1988; Reitz \& Callender, 1993; Siminoff \& Arnold, 1999; Siminoff \& Chillag, 1999; Spigner, et al., 1999; Yancey, et al., 1997; Yuen, et al., 1998), and a desire to maintain bodily integrity (McNamara, et al. 1999; Rubens \& Oleckno, 1998; Spigner, et al., 1999) are the major reasons cited by researchers for African Americans' unwillingness to donate organs.

Morgan and Cannon (2003) conducted a study of 300 African American adults in New Jersey, which demonstrated that there are key barriers that require particular attention when targeting African Americans with organ donation messages. Respondents were asked eight knowledge questions about organ donation. The level of knowledge displayed by people who had already signed organ donor cards was significantly higher (an average of 5.14 correct responses) than those who had not signed a card (an average of 3.72 correct responses). Five items in particular strongly distinguished donors from non-donors: the belief that racial discrimination plays a role in organ allocation, the belief that organ 
donation is associated with additional medical costs, the belief that organ allocation is more likely to favor the rich over the poor, a misunderstanding of brain death, and the belief that a black market for organs exists in the U.S. These are clearly important knowledge items to target in future organ donation promotion efforts in the African American community since they clearly (and strongly) differentiate donors from non-donors.

A campaign targeting African-Americans in Charlotte, North Carolina was one of the first projects focusing specifically on DMV branch offices targeting African Americans. For this project, brochures developed by The Coalition for Donation that targeted African Americans were further tailored to the specific concerns and needs of African Americans listed above. The rationale for using the DMV as an important site for the dissemination of organ donation information is because people are asked whether they want to be organ donors at the DMV, precisely at a time when they are unlikely to be carefully considering this issue. The campaign was successful with the targeted population. The campaign produced a $6 \%$ increase in the rate of donor registrations (from $23 \%$ to $29 \%$ ) in less than one year. As a relative increase over the baseline, this represents a $26 \%$ improvement in registration rates among African Americans, and resulted in thousands of new and unique registrations. Registrations also increased among non-African Americans, who were not targeted by the campaign. However, this rate of increase was less than half of that of African Americans (Morgan, unpublished manuscript), demonstrating the importance of well-tailored and targeted messages.

\subsubsection{The drive for life campaign}

A second strategy for DMV based campaigns involves training DMV clerks about organ donation, and how to talk to the public about donation. While creating and managing organ donor registries through DMVs has many advantages, one of the disadvantages is that the clerks who staff DMV offices are not specialists in organ donation. Their primary job is to handle the business of the state as it relates to motor vehicles. As such, it is unrealistic to expect DMV employees to be passionate or knowledgeable about organ donation. The personal experience of two of the investigators involved with the project was that DMV clerks sometimes provided misinformation about organ donation unwittingly, and in the worst cases, actively discouraged members of the public not to designate their donor status on their license. Of course, this should not be surprising since DMV clerks cannot be expected to be better educated about organ donation than the general public. Even when OPOs provide periodic "training" (presentations) with clerks, these trainings are often sporadic, brief, and not tailored to the interactions that can be expected to occur between DMV clerks and members of the public. Thus, it appears that two barriers to the utilization of DMV-based donor registries are DMV clerk inaction (e.g. not asking people whether they would like to be a donor before laminating their licenses), and the dissemination of inaccurate information (e.g. "I won't do it myself because I know they'd let me die to get my organs").

A DMV clerk training intervention was designed to coincide with the start of a new DMV based registry that was approved by the Kentucky legislature in 2006. Just prior to the launch of the registry Harrison and colleagues (2008) conducted trainings of DMV clerks in 8 counties. Additionally, 4 counties were chosen as control counties and were matched as closely as possible on demographics. An initial survey of DMV clerks revealed attitudes and 
knowledge about donation that were not significantly different than that of the general population of the rest of the state. While not unexpected, this particular group of clerks had voluntarily set up a non-profit organization to promote donation and were highly supportive of the organ donation and the organ donor registry. However, even with knowledge on par with that of the general public, the clerks were tasked with talking to the public about organ donation and asking them to join the new registry.

To help overcome knowledge barriers and to increase confidence in communicating with the public about organ donation, Harrison and colleagues (2008) created a one-hour training program that covered the fundamentals of how the new registry worked (e.g. who has access to the registry, how names can be removed, etc.), basic myths and facts about organ donation based on common misperceptions that keep people from becoming donors (e.g. belief in a black market, religious beliefs about donation, brain death, medical mistrust, deservingness of recipients, problems with organ allocation, etc.). Additionally, the clerks were trained in communication techniques to enhance their persuasiveness, or at least neutrality, in asking people to join the registry (e.g. framing questions in the positive, providing short answers to questions, maintaining positive nonverbal cues, etc.). Additionally, clerks were provided with a training manual full of facts about the registry, communication strategies, and facts and myths about donation, "at-a-glance" answers to common misperceptions, and a script on the best way to ask people to join the registry. Clerks were surveyed after the trainings and there were significant increases in knowledge and attitude across all dimensions related to organ donation.

Overall, the trainings of drivers license bureau clerks proved to be highly successful, with rates of joining the organ donor registry for the first six months after the trainings $14 \%$ higher than control counties and 9\% higher than the overall statewide average. This translates into thousands of new registries each month as a direct result of clerk trainings, and potentially into thousands of lives saved over time. However, over time the rates of new registries started to decrease, in spite of our best efforts to provide motivation to encourage clerks to maintain their positive communication strategies. These motivational strategies included letters from recipients and donor families, competition between branches, and onsite visits to check in with clerks, and did result in short term recovery after these motivational efforts.

In a similar study, Rogridgue and colleagues (under review) developed a series of interventions targeted at DMV staff in Florida, including training DMV staff about myths and barriers to organ donation and the importance of positive communication with members of the public. In addition to the standard brochures related to organ donation, the intervention also included periodic visits by staff and volunteers to provide information to the public about donation. During the intervention period rates of registration increased by approximately $10 \%$ (i.e. from $32.4 \%$ to $35.9 \%$ ), although increases varied by region, with areas with higher minority populations seeing lower increases. As with the Kentucky DMV study, after the initial intervention period rates of joining the registry decreased slightly in intervention counties, even though presumably the same clerks who were trained were still interacting with the public. The gradual decreases found in both studies involving clerk trainings suggests an area of future research: how to keep clerks motivated to put on a positive face toward organ donation when faced with countless negative reactions. 


\subsubsection{The Michigan Tell Us Now DMV campaign}

While some DMVs require clerks to ask the public to join the organ donor registry, other states have different requirements. Michigan's policy has been that the public must directly request the clerk in order to join the registry, rather than having clerks ask if they wish to join. As such, training clerks about organ donation was not a viable option. Additionally, this policy likely contributed to Michigan having one of the lowest percentages of the public joining the registry in the entire U.S. A series of phased interventions were constructed by Harrison and colleagues (Harrison et al. 2010; Harrison et al. 2011; King et al. under review) to help overcome this barrier to joining the registry and increase the number of people in Michigan who had declared their intent to become donors.

There were three primary elements to the Michigan interventions. First, point-of-decision (POD) materials were placed in all branch offices in intervention counties. POD materials were designed to prime the public about donation and ran for the entire six months of each intervention in each county. Messages were designed using principles from the Organ Donor Model (Morgan et al., 2002) to address knowledge and social norms about donation. The placement of materials was determined by principles of communication design (e.g. Aakhus, 2007; Harrison et al. 2010; Jackson, 1998) to encourage positive interactions about organ donation. Materials for each set of interventions modified for the target audiences of each county. Additionally, materials were designed to be encountered at every step of the process until the final interaction with the DMV clerk where they could designate themselves as donors on the registry.

Materials included posters (see figure 1) featuring local community members who had been touched by donation to encourage positive social norms about donation. Local community members were chosen over celebrities as one of the key barriers to donation in the U.S. is the belief that the rich and famous are far more likely to get transplants than a member of the general public (Morgan et al., 2005). Additional materials included footprints with organ donation messages (placed along common routes throughout the DMV offices), "clerk cards" (see figure 2) that were handed to individuals on check-in with a simple message to give the card to a clerk if they wanted to be a donor, and counter-mats (see figure 3) where customers signed paperwork at clerks' stations which again prompted them to be donors. Additionally, standard information brochures were available throughout the offices.

The second component of the intervention included a mass media campaign. The mass media campaign ran in conjunction with POD materials for the first four months of the campaign in each intervention county. Mass media components included a series of 30 or 60 second radio PSAs featuring stories of individuals touched by organ donation, and concluded with a tag line asking customers to "Tell Us Now" that they wanted to be a donor. In addition to radio PSAs there were a series of billboards (see figure 4) using the same stories and visuals that appeared in the POD materials. These billboards were placed on the approach to each DMV branch office to further prime individuals to think about becoming a donor prior to entering the branch office. In more heavily populated areas billboards were placed on the outsides of buses running through target neighborhoods. Again, materials were tailored to the primary target audience of the campaign. 


\section{Tell Us Now that you want to be an organ donor!}

Brandon's decision to be a donor gave life to five others.

Last year, $22 \%$ of Michigan donors and $33 \%$ of Michigan transplant recipients were ethnic minorities.

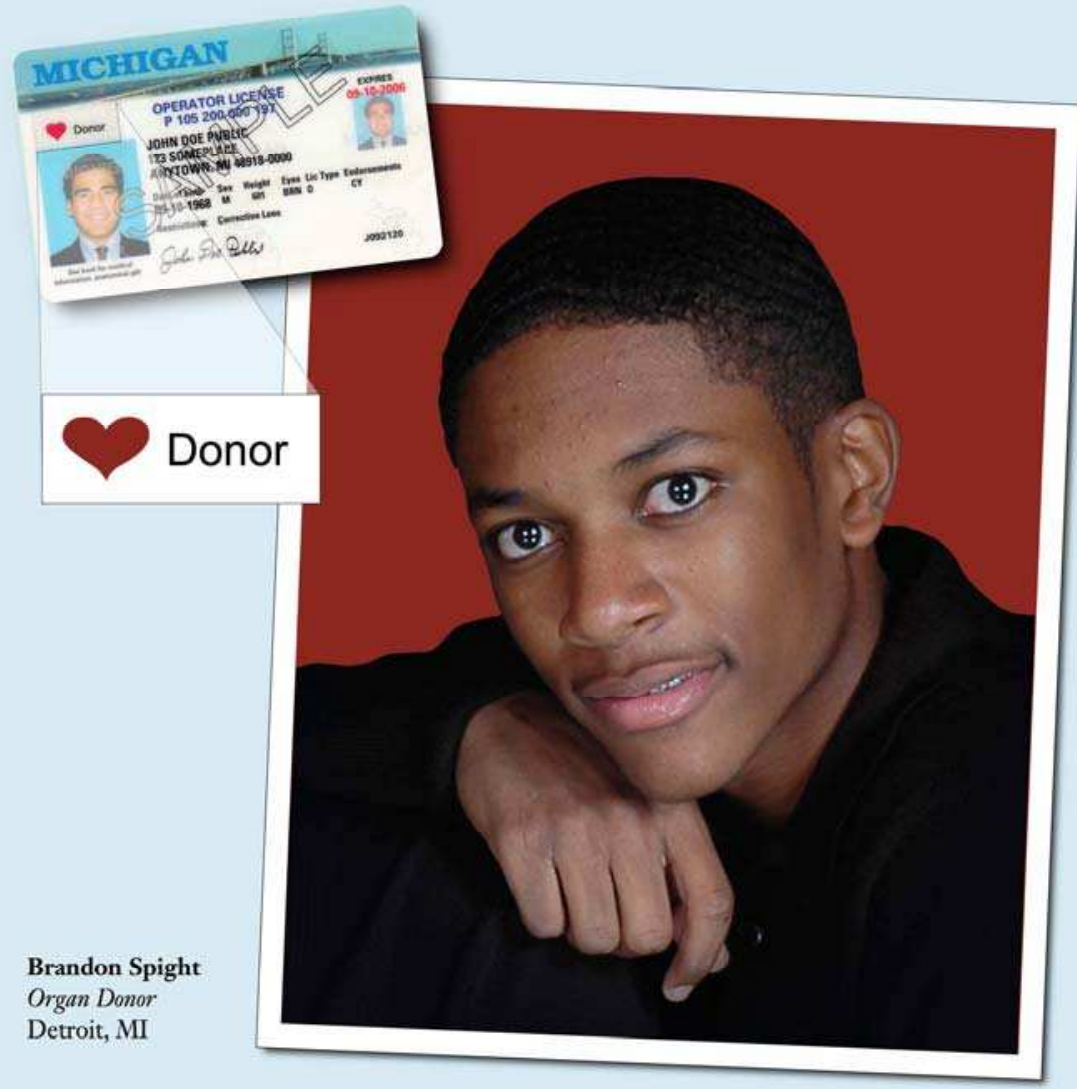

Fig. 1. Example of Poster Featuring Local Community Member Touched by Donation. 

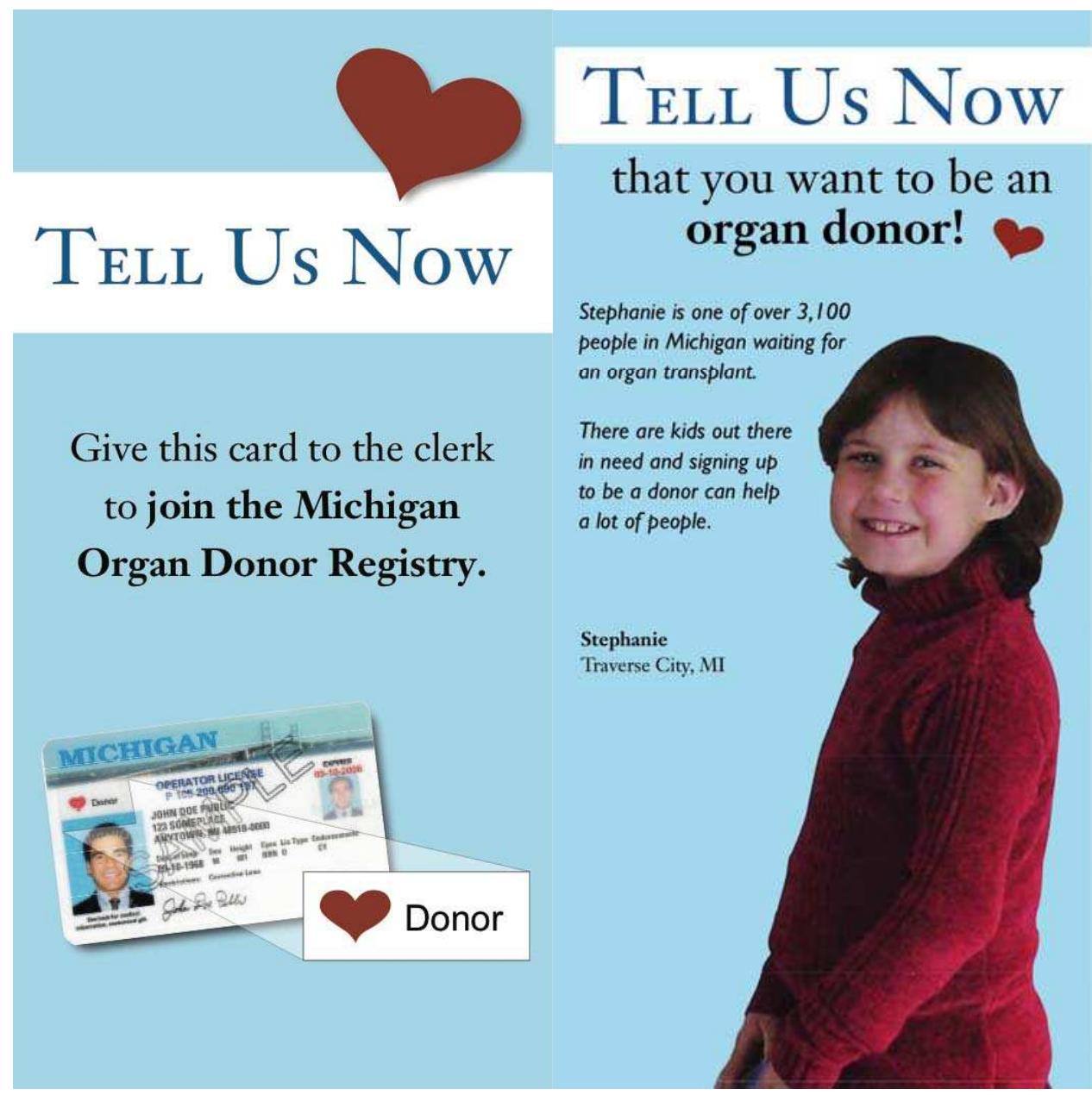

Fig. 2. Example of Clerk Card Front and Back

\section{Tell Us Now} that you want to be an organ donor!

Stephanie is one of over 3,100 people in Michigan waiting for an organ transplant.

There are kids out there in need and signing up to be a donor can help a lot of people.

Stephanie

Traverse City, MI 


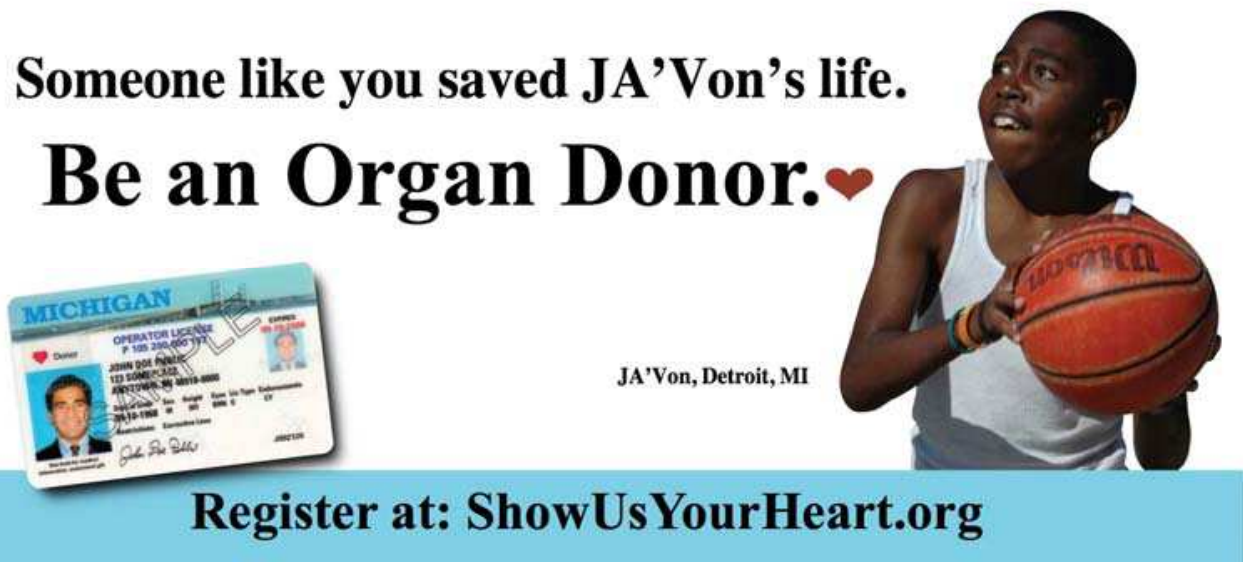

Fig. 4. Sample Billboard

A final component to the intervention consisted of an interpersonal intervention where volunteers associated with the local organ procurement organization (OPO) covered shifts in branch offices to talk to members of the public about joining the registry. Most volunteers had been touched by organ donation, either as recipients, in need of a transplant, or donor family members. The interpersonal component occurred during months 3 and 4 of the 6month intervention. During these two months all other elements of the campaign (POD, mass media) were also included. All volunteers underwent specialized training that was modified from the Kentucky project and from two previous worksite campaigns (Morgan, Stephenson et al. 2010; Morgan, Harrison et al. 2010). The training was necessary because simply being touched by donation does not mean an individual knows all of the facts about donation or the best ways to talk to the public about donation. Volunteers wore "uniforms" with polo shirts displaying the "Tell Us Now" logo. Volunteers were placed in branch offices for four four-hour shifts per week and greeted every individual who entered DMV branch offices, handed them a "clerk card", and if any individual showed extra interest or had questions, talked to them about organ donation.

The first two phases of our interventions took place in predominately Caucasian counties (Harrison et al. 2010). Results showed that media messages plus POD materials were able to increase the number of people joining the registry by $200 \%$ and the addition of the interpersonal component raised that rate to between 300 and $380 \%$. When mass media and interpersonal components were removed, POD materials continued to generate an approximately $200 \%$ increase compared to baseline. When we conducted our campaign in predominately African American neighborhoods using messages tailored for that population we saw even more dramatic results (Harrison et al., 2011). In zip codes with a population of $80 \%$ or more African Americans, we saw increases of $380 \%$ for media and POD materials, and over $1250 \%$ increase with the addition of the interpersonal component. POD material alone still resulted in increases of over $250 \%$ compared to baseline. Surprisingly, given many of the concerns expressed by African Americans about organ donation, we were able to increase the number of people registering to be donors to the same rate as Caucasians. Overall, in just over a year of interventions across five counties we were able to add over 60,000 unique registries above baseline data. 
At the completion of the intervention in our initial 5 counties, POD materials were placed throughout DMV branch offices across the state, and an evaluation was completed on the impact of POD materials in the absence of mass media or interpersonal components (King et al., under review). When POD materials were introduced at DMV branch offices in an additional 34 (much smaller population) counties, registrations increased approximately $50 \%$ (i.e. from $9.1 \%$ to $14.6 \%$ ), and over the course of 6 months generated almost 9,000 new and unique registrations over baseline. While POD materials alone do not generate as many registries as when combined with the interpersonal component, the placement of POD materials is essentially a one-time occurrence. As such, the return for very limited investment of resources is quite large.

\subsection{Cost effectiveness of DMV campaign components}

Creating and running public education campaigns can be a very expensive endeavor. Most OPOs and other non-profit and governmental agencies have limited resources and are thus looking to maximize the return on those resources. King et al. (under review) analyzed costs per registry for the different campaign strategies in the Michigan projects. The most cost effective way to increase registries is by using just POD materials. The cost per registry in the 34 counties that received only POD materials was $\$ 1.34$ per registry. The campaigns that included the media components cost between $\$ 12$ and $\$ 34$ dollars per registry (the cost varied as a result of population size, the cost of the media market, and differences in registration rates of the different counties). However, given the apparently limited impact of the media, removing that cost from the estimates, and including only the POD materials and costs associated with managing volunteers, King reports costs ranging from $\$ 1.30$ to $\$ 3.10$. While POD materials may generate registries for the lowest cost, they don't reach as wide an audience, and many people who might be persuaded to join the registry are missed as a result. Based on the massive increases found when volunteers were on site, it appears that the use of POD materials with an interpersonal volunteer component may give not only the best value, but also reach a much broader segment of the population, resulting in higher overall numbers on organ donor registries. Regardless, if we go by earlier assumptions on rates of consent and eligible donors, adding 200 names to a registry should result in one new donor over a lifetime. Even at a cost of $\$ 34$ per registry, the cost is only $\$ 6,800$ to secure one donor (with an average of three organs). On the low end of $\$ 1.30$ per registered donor, the cost per actual donor is closer to the $\$ 250$ range. It is hard to imagine anyone objecting to spending $\$ 250$ - $\$ 6,800$ to save three lives. These figures suggest that OPOs should take a long-range view of public education, registries, and the donation process and commit the resources necessary to fill organ donor registries. While there are not direct cost comparisons available for clerk trainings, trainings in the Kentucky project cost approximately $\$ 35$ per clerk (food during the training and a \$25 gift card to a local store to compensate for their time) plus the cost of someone to do the trainings and follow up. This is a very low cost investment considering the ongoing benefits of clerk interactions.

Unfortunately, at this stage no research has been done to examine how many individuals who sign up on the registry actually become donors. However, given the arguments made earlier in the chapter, this is not an appropriate evaluation. Registries are designed for longterm benefits, with the number of donors considered over an average lifetime. What we do know is that if a potential donor is listed on a registry, they are significantly more likely to become actual donors than if they were not on the registry. The estimates provided earlier demonstrate how significant organ donor registries can be. 


\subsection{Structural issues for organ donor registries}

We concur with The Lewin Group report (2002) that a successful registry is one which registers as many willing citizens as possible as potential donors. Registries that make it inconvenient for people to join will clearly miss many thousands of opportunities for people to join, thus reducing the potential pool of declared donors for whom "first person consent" can be secured, or in the cases of "registries of intent", providing evidence to family members of the wishes of the deceased. DMV-based registries are convenient and are squarely in the path of the majority of Americans. Any barriers to registering at DMVs (including the lack of information to make an on-the-spot decision) should be removed to further maximize utilization of the registry (The Lewin Group, 2002). Based on experiences from the previous campaigns, I suggest the following as guidelines in thinking about the development of the most effective registries.

- Registries should be housed with an agency that requires all (or at least the vast majority) of its citizens to actually come in person on a semi-regular basis and complete some form of mandatory transaction.

- Clerks should be trained in how to (persuasively) ask if an individual would like to join the registry, and to provide brief, accurate answers to questions about organ donation.

- $\quad$ The process should be as simple as swiping an ID card through a machine or hitting a single key to indicate desired status.

- Well-designed POD materials should be placed strategically to enhance their effectiveness as individuals engage in their normal transactions.

- Space should be provided for volunteers to set up information booths and to greet and talk with customers about organ donation.

- There should be an online version of the registry. Online registries should be easy to complete, not require a witness or the mailing in of a secondary card to verify signatures, and should have the full force of joining in person. One possible way for verification is through asking for a national identity number, social security number, or state ID number.

- Registries should have an easy mechanism in place so individuals can remove their names if they change their minds.

- While registries of consent seem to be working well in the U.S., cultural or national considerations should be taken into account and registries of intent may suffice in some contexts.

- Data should be updated in real-time and registry information should be easily accessible to those who are authorized for access.

DMV-based registries have an additional potential advantage for OPOs: They provide the opportunity to measure, in real time, actual behavior change occurring in each part of the OPO's territory. This means that concentrated bursts of public education outreach efforts with a particular population in a particular city can be evaluated on the basis of whether an increase in donor registrations has occurred. These numbers can be compared to baseline measures (the previous six months, or the number of registrations during a particular month the previous year). Of course, not all people who have been swayed by a particular outreach effort will find themselves at the DMV within weeks or months of an intervention; however, an increase in registrations will nonetheless provide a measure of the impact of a relatively large-scale intervention (e.g. a special effort to organize many churches to observe a Donor Sabbath, or the success of a media-based campaign during Donor Awareness month). 


\section{International perspectives and adaptation}

One of the most important factors involved in consent to donation of a loved one's organs appears to be knowledge by the family of the wishes of the deceased. While registries are an excellent way to document these wishes and to provide compelling proof to the family of those wishes, registries may not be feasible in all countries or systems of organ donation. For example, in countries that have an "opt-out" system, whereby everyone is presumed to be a donor unless they have made notification of their desire not to be a donor, a registry of those wishing to be organ donors seems counterproductive. However, many of the countries that have an "opt-out" system still rely on family consent before recovering and transplanting organs (see Gevers, et al. 2004 for discussion of policy versus practice). While countries like Spain have tremendous success at achieving family consent, other countries have much lower rates of success. Campaigns that work toward some degree of documentation or family notification can serve much the same purpose as a full-fledged registry. As with registry-based campaigns, though, the focus should be on reaching large segments of the population and providing some sort of clear documentation of the wishes of the individual.

Countries who are developing systems of organ donation or who follow an "opt-in" model should consider the creation of regional or national registries. If countries are in the early stages of such a process, developing a unified data set and using common programs and programming languages will make for a system that is more easily accessed, expanded, and shared. Additionally, the more types of data that an be included on the registry, the more useful of a tool it becomes for evaluating trends and developing campaigns to target specific populations that register at lower rates to become potential donors. Examples of data that are useful from a campaign/evaluation perspective include zip code data, gender, race/ethnicity, and age. While many other types of data are useful, this type of information is often collected during DMV or identity card processes.

While many of the messages used in the campaigns are targeted toward specific U.S. population groups, many of the barriers to donation are very similar across different cultural and ethnic groups (e.g. lack of knowledge about brain death, fears of a black market, medical mistrust, perceived religious beliefs) and messages can be easily adapted to meet the needs of specific target audiences. To create effective persuasive informative campaigns, researchers and practitioners should attend to both the type and quantity of information sources (Ganikos, et al., 1994) as well as the type of message. Previous studies have shown that some types of knowledge can be low and yet not affect the willingness to donate, while other types of misconceptions can be critical to the decision to donate (Morgan \& Miller, 2002; Morgan et al., 2003). Therefore, focusing on specific knowledge barriers rather than on general awareness is more likely to yield positive campaign effects. Additionally, while communication norms are different based on country, culture, and ethnicity, training key gatekeepers, volunteers, or staff members about best communication practices is key. This includes developing scripts about how to get individuals to declare intent to donate, addressing common myths and barriers to donation, telling personal stories about donation, and talking to family members about consenting to donation. Finally any campaign should be constructed on solid theoretical foundations. Variations of the Theory of Reasoned Action or the Theory of Planned Behavior that target knowledge, attitude, and social norms have seemed to work well for campaigns about deceased donation. More recently there has also been a focus on non-cognitive barriers to donation (see Morgan, 2012 for an excellent review of theoretical approaches to organ donation campaigns). 


\section{Conclusion}

When families are aware of the wishes of a deceased loved one, rates of consent to donation are much higher than when they are not aware of those wishes. One mechanism to insure families have knowledge of a loved one's wishes is through an individual's enrollment on an organ donor registry. Organ donor registries run through DMV offices (or some similar type of agency or structure) take advantage of the law of large numbers and have the ability to quickly add large numbers of individuals to organ donor registries, thus increasing rates of consent and ultimately saving lives. Additionally, campaigns that focus on training clerks about how registries work, common facts and myths related to organ donation, and how to communicate about organ donation is one strategy that has proven effective in increasing the number of individuals who join organ donor registries. Additionally, providing theoretically driven, well-designed and well-placed POD material, and having volunteers or OPO staff members engage in interpersonal communication about organ donation increase the rates at which individuals join registries. These strategies have proven successful across multicultural populations, and campaign messages can be easily tailored to the concerns of different countries or cultures.

\section{Acknowledgements}

The author would like to acknowledge the many individuals whose intellectual contributions, boundless energy, support, and creativity were invaluable toward the success of several of the projects discussed in this chapter. They include Susan Morgan, Mark Di Corcia, Andy King, Elizabeth Williams, Paula Hopeck, Tammie Havermahl, Monica Johnson, Jenny Miller Jones, Rebecca Ivic, Mary Ganikos, and the many remarkable volunteers and staff members whose dedication to organ donation continues to make work like this possible.

\section{References}

Aakhus, M. (2007). Communication as design. Communication Monographs, Vol. 74, pp. 112117, ISSN 0363-7751

Arnason, W. B. (1991). Directed donation: The relevance of race. Hastings Center Report, Vol. 21 No. 6, pp. 13-19, ISSN 0093-0034

Conesa, C., Rios, A., Ramirez, P., Canteras, M., Rodriguez, M. M. \& Parrilla, P. (2006). Attitudes toward organ donation in rural areas of Southeastern Spain. Transplantation Proceedings, Vol. 38, pp. 866 - 868, ISSN 0041-1345

Donate Life America, (2011). Number of organ, eye, and tissue donors continues to rise. Retrieved August 15, 2011 from http:/ / donatelife.net/number-of-registered-organeye-tissue-donors-continues-to-rise

Fahrenwald, N. L., Belitz, C., \& Keckler, A. (2010). Outcome evaluation of 'Sharing the Gift of Life': An organ and tissue donation educational program for American Indians. American Journal of Transplantation, Vol. 10, pp. 1453 - 1459, ISSN 1600-6143

Feeley, T. H., Anker, A. E., Watkins, B., Rivera, J., Tag, N., Volpe, L. (2009). A peer-to-peer campaign to promote organ donation among racially diverse college students in New York City. Journal of the National Medical Association, Vol. 101, pp. 1154 - 1162, ISSN 0027-9684 
Ganikos, M. L., McNeil, C., Braslow, J. B., Arkin, E. B., Klaus, D., Oberley, E. E., \& White, M. F. (1994). A case study in planning for public health education: The organ and tissue donation experience. Public Health Reports, Vol. 109, No.5, pp. 626-631, ISSN 0033-3549

Gevers, S., Janssen, A., Friele, R. (2004). Consent systems for post mortem organ donation in Europe. European Journal of Health Law: Vol. 11, No. 2, pp. 175-186. ISSN 0929-0273.

Harrison, T. R., Morgan, S. E., \& Di Corcia, M. J. (2008). The impact of organ donation education and communication training for gatekeepers: DMV clerks and organ donor registries. Progress in Transplantation, Vol. 18, pp. 301 - 309, ISSN 1526-9248

Harrison, T. R., Morgan, S. E., King A. J., Di Corcia, M. J., Williams, E. A., Ivic, R. K., \& Hopeck, P. (2010). Promoting the Michigan Organ Donor Registry: Evaluating the impact of a multifaceted intervention utilizing media priming and communication design. Health Communication, Vol. 25, pp. 700 - 708, ISSN 1523-0236

Harrison, T. R., Morgan, S. E., King A. J., \& Williams, E. A. (2011). Saving lives branch by branch: The effectiveness of driver licensing bureau campaigns to promote organ donor registry sign-ups to African Americans in Michigan. Journal of Health Communication, Vol. 16, No. 8, pp. 805 - 819, ISSN 1081-0730

Health Resources Services Administration, (2006). Retrieved August 10, 2006 from http://newsroom.hrsa.gov/newssummary/march2006.

Jackson, S. (1998). Disputation by design. Argumentation, 12, pp. 183-198, ISSN 0920-0427

King, A. J., Williams, A. E., Harrison, T. R., \& Morgan, S. E. (under review) The 'Tell Us Now' Campaign for Organ Donation: Impact of Point-of-Decision Messages Promoting a DMV-Based Registry.

Lewin Group, The (2002). Guidelines for donor registry development conference: Final report. Contract HHS-GS-23F-9840H. Accessible from www.hrsa.gov.

Molzahn, A. E., Starzomski, R., McDonalk, M., \& O'Loughlin, C. (2005). Chinese Canadian beliefs toward organ donation. Qualitative Health Research, Vol. 15, pp. 82 - 98, ISSN 1049-7323

McNamara, P., Guadagnoli, E., Evanisko, M. J., Beasley, C., Santiago-Delpin, E. A., Callender, C. O., Christiansen, E. (1999). Correlates of support for organ donation among three ethnic groups. Clinical Transplantation, Vol. 13, pp. 45-50, ISSN $0902-$ 0063

Morgan, S. E. (unpublished manuscript). Final report of the Grassroots and media campaign to promote organ donation among African Americans in North Carolina.

Morgan, S. E. (in press). Public communication campaigns to promote organ donation: Theory, design, and implementation. In R. Rice \& C. Atkin (Eds.) Public Communication Campaigns. Thousand Oaks, CA: Sage Publications. ISBN

Morgan, S.E. and Cannon, T. (2003) African Americans' knowledge about organ donation: Closing the gap with more effective persuasive message strategies. Journal of the National Medical Association, Vol. 95, No. 11, pp. 1066-1071, ISSN 0027-9684

Morgan, S. E., Harrison, T. R., Long, S., Afifi, W., Stephenson, M., and Reichert, T. (2005). Family discussions about organ donation: How the media influences opinions about donation decisions. Clinical Transplantation, Vol. 19, pp. $674-682$, ISSN 09020063 
Morgan, S. E. and Miller, J. (2002). Beyond the organ donor card: The effect of knowledge, attitudes, and values on willingness to communicate about organ donation to family members. Health Communication, Vol. 14, No. 1, pp. 121-134, ISSN 1523-0236

Morgan, S. E., Miller, J., and Arasaratnam, L. A. (2002). Signing cards, saving lives: An evaluation of the Worksite Organ Donation Promotion Project. Communication Monographs, Vol. 69, No. 3, pp. 253-273, ISSN 0363-7751

Morgan, S. E., Miller, J., and Arasaratnam, L. A. (2003). Similarities and differences between African Americans' and European Americans' attitudes, knowledge, and willingness to communicate about organ donation. Journal of Applied Social Psychology, Vol. 33, No. 4, pp. 693 - 715, ISSN 0021-9029

Morgan, S. E., Harrison, T. R., Chewning, L. V., Di Corcia, M., \& Davis, L. (2010) The effectiveness of high- and low-intensity worksite campaigns to promote organ donation: The Workplace Partnership for Life. Communication Monographs, Vol. 77, pp. 341 - 356. ISSN 0363-7751

Morgan, S. E., Miller, J., \& Arasaratnam, L. A. (2002). Signing cards, saving lives: An evaluation of the Worksite Organ Donation Promotion Project. Communication Monographs, Vol. 69, pp. 253 - 273, ISSN 0363-7751

Morgan S.E., Stephenson M.T., Afifi W., Harrison T.R., Long S.D., \& Chewning L.V. (2010). The University Worksite Organ Donation Project: a comparison of two types of worksite campaigns on the willingness to donate. Clinical Transplantation, DOI: 10.1111/j.1399-0012.2010.01315.x ISSN 0902-0063

Organ Procurement and Transplantation Network, (2011). Retrieved August 15, 2011 from http://optn.transplant.hrsa.gov/latestData/rptData.asp

Punch, J.D., Hayes, D. H., LaPorte, F. B., McBride, V., \& Seely, M. S. (2007). Organ Donation and Utilization in the United States, 1996 - 2005. American Journal of Transplantation, Vol. 7 (part 2), pp. 1327 - 1338, ISSN 1600-6143

Quinn, M. T., Alexander, G. C., Holingsworth, D., O'Connor, K.G., \& Meltzer, D. (2006). Design and evaluation of a workplace intervention to promote organ donation. Progress in Transplantation, Vol. 16, pp. 253 - 259, ISSN 1526-9248.

Reitz, N. N. \& Callender, C. O. (1993). Organ donation in the African American population: A fresh perspective with a simple solution. Journal of the National Medical Association, Vol. 85, pp. 353-358, ISSN 0027-9684

Rodrigue, J. R., Cornell, D. L. \& Howard, R. J. (2005). The American Journal of Transplantation, Vol. 6, pp. 190 - 198, ISSN 1600-6143

Rodrigue, J. R., Krouse, J., Carroll, C., McMillen, L., Giery, K. Fraga, Y., Frost, T., \& Edwards, E. (under review). A Department of Motor Vehicles intervention yields moderate increases in donor designation rates.

Rubens, A.J., \& Oleckno, W. A. (1998). Knowledge, attitudes, and behaviors of college students regarding organ and tissue donation and implications for increasing organ/tissue donors. College Student Journal, Vol. 32, pp. 167-178, ISSN 0146-3934

Siminoff, L. A., \& Lawrence, R. H. (2002). Knowing patients' preferences about organ donation: Does it make a difference? The Journal of Trauma: Injury, Infection, and Critical Care, Vol. 53, pp. 754 - 760, ISSN 0022-282

Siminoff, L. A., \& Arnold, R. M. (1999). Increasing organ donation in the African American community: Altruism in the face of an untrustworthy system. Annals of Internal Medicine, Vol. 130, pp. 607-609, 0003-4819 
Siminoff, L. A. \& Chillag, K. (1999). The fallacy of the "gift of life." Hastings Center Report, Vol. 29, pp. 34-41, ISSN 0093-0334

Spigner, C., Weaver, M., Pineda, M., Rabun, K., French, L., Taylor, L., \& Allen, M. D. (1999). Race/ethnic-based opinions on organ donation and transplantation among teens: Preliminary results. Transplantion Proceedings, Vol. 31, pp. 1347-1348, ISSN 00411345

Topbas, M., Can, G., Can, M. A., \& Ozgun, S. (2005). Outmoded attitudes toward organ donation among Turkish health care professionals. Transplantation Proceedings, Vol. 37, pp. 1998 - 2000, ISSN 0041-1345

United Network for Organ Sharing (UNOS), 2011. www.unos.org, retrieved August 15, 2011.

Vidal, M. M., Castell, R. C., Zapata, D. P., \& Duarte, G. P. (2007). Transplant procurement management: Transplant coordination organization model for the generation of donors. In R. Valero (Ed.) Transplant Coordination Manual, pp. 9-26. Limpergraf, S.L.: Barbera del Valles, Spain, ISBN 978-84-612-0565-3

Wittig, D. R. (2001). Organ donation beliefs of African Americans residing in a small Southern community. Journal of Transcultural Nursing, Vol. 12, No. 3, pp. 203-210, ISSN 1043-6596

Yancey, A. K., Coppo, P., \& Kawanishi, Y. (1997). Progress in availability of donors of color: the national marrow donor program. Transplantation Proceedings, Vol. 29, pp. 37603765, ISSN 0041-1345

Yuen, C. C. Burton, W., Chiraseveenuprapund, P., Elmore, E., Wong, S., Ozuah, P., \& Mulvihill, M. (1998). Attitudes and beliefs about organ donation among different racial groups. Journal of the National Medical Association, Vol. 90, pp. 13-18, ISSN 0027-9684 


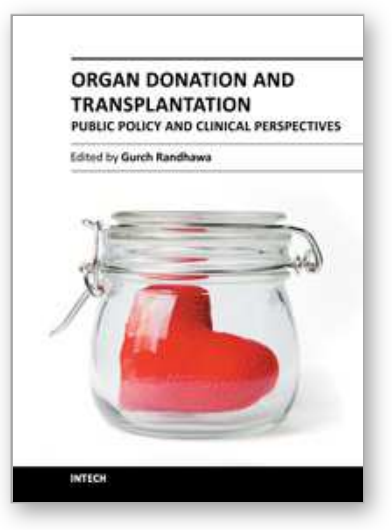

\author{
Organ Donation and Transplantation - Public Policy and Clinical \\ Perspectives \\ Edited by Dr. Gurch Randhawa
}

ISBN 978-953-51-0039-3

Hard cover, 284 pages

Publisher InTech

Published online 08, February, 2012

Published in print edition February, 2012

Transplantation has succeeded in prolonging the lives of those fortunate enough to have received the gift of a body organ. Alongside this life-saving development, there lies another sadder side to the story - there are not enough organs to meet the ever increasing demand. This not only places an increasing emotional and physical burden among the waiting patients and families but heaps a great financial burden upon health services. This book provides an analysis and overview of public policy developments and clinical developments that will hopefully ensure an increased availability of organs and greater graft survival. Medical, policy, and academic experts from around the world have contributed chapters to the book.

\title{
How to reference
}

In order to correctly reference this scholarly work, feel free to copy and paste the following:

Tyler R. Harrison (2012). Increasing the Likelihood of Consent in Deceased Donations: Point-of-Decision Campaigns, Registries, and the Law of Large Numbers, Organ Donation and Transplantation - Public Policy and Clinical Perspectives, Dr. Gurch Randhawa (Ed.), ISBN: 978-953-51-0039-3, InTech, Available from: http://www.intechopen.com/books/organ-donation-and-transplantation-public-policy-and-clinicalperspectives/increasing-the-likelihood-of-consent-in-deceased-donations-point-of-decision-campaignsregistries-an

\section{INTECH}

open science | open minds

\author{
InTech Europe \\ University Campus STeP Ri \\ Slavka Krautzeka 83/A \\ 51000 Rijeka, Croatia \\ Phone: +385 (51) 770447 \\ Fax: +385 (51) 686166 \\ www.intechopen.com
}

\author{
InTech China \\ Unit 405, Office Block, Hotel Equatorial Shanghai \\ No.65, Yan An Road (West), Shanghai, 200040, China \\ 中国上海市延安西路65号上海国际贵都大饭店办公楼 405 单元 \\ Phone: +86-21-62489820 \\ Fax: +86-21-62489821
}


(C) 2012 The Author(s). Licensee IntechOpen. This is an open access article distributed under the terms of the Creative Commons Attribution 3.0 License, which permits unrestricted use, distribution, and reproduction in any medium, provided the original work is properly cited. 